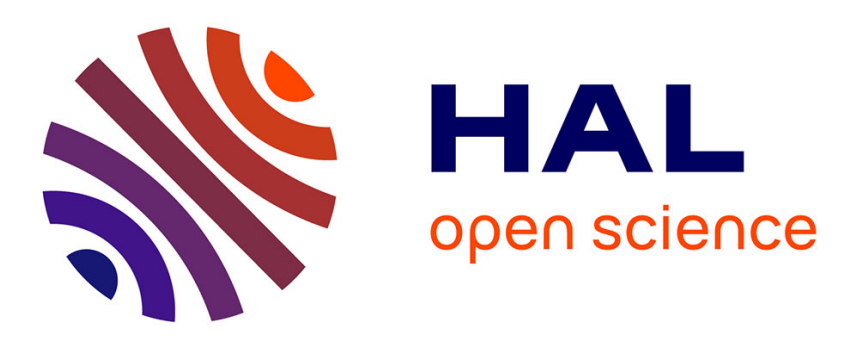

\title{
Assessment of a new fabrication route for Fe-9Cr-1W ODS cladding tubes
}

Louise Toualbi, Cyril Cayron, Patrick Olier, Joël Malaplate, Mathilde Praud, Marie-Helene Mathon, Didier Bossu, Elodie Rouesne, Alexandre Montani, Roland E. Logé, et al.

\section{To cite this version:}

Louise Toualbi, Cyril Cayron, Patrick Olier, Joël Malaplate, Mathilde Praud, et al.. Assessment of a new fabrication route for Fe-9Cr-1W ODS cladding tubes. Journal of Nuclear Materials, 2012, 428 (1-3), pp.47-53. 10.1016/j.jnucmat.2011.12.013 . hal-00679120

\section{HAL Id: hal-00679120}

https://hal-mines-paristech.archives-ouvertes.fr/hal-00679120

Submitted on 21 May 2012

HAL is a multi-disciplinary open access archive for the deposit and dissemination of scientific research documents, whether they are published or not. The documents may come from teaching and research institutions in France or abroad, or from public or private research centers.
L'archive ouverte pluridisciplinaire HAL, est destinée au dépôt et à la diffusion de documents scientifiques de niveau recherche, publiés ou non, émanant des établissements d'enseignement et de recherche français ou étrangers, des laboratoires publics ou privés. 


\section{Assessment of a new fabrication route for $\mathrm{Fe}-9 \mathrm{Cr}-1 \mathrm{~W}$ ODS cladding tubes}

L. Toualbi ${ }^{1}$, C. Cayron ${ }^{2}$, P. Olier ${ }^{3}$, J. Malaplate ${ }^{4}$, M. Praud ${ }^{5}$, M.-H. Mathon ${ }^{6}$, D. Bossu ${ }^{7}$, E. Rouesne ${ }^{8}$, A. Montani $^{9}$, R. Logé ${ }^{10}$, Y. de Carlan ${ }^{11}$

${ }^{1}$ Nuclear Materials Department, CEA Saclay, 91191 Gif-sur-Yvette, France, louise.toualbi@cea.fr

${ }^{2}$ Laboratory of Innovation for New Energy Technologies and Nanomaterials, PFNC, Minatec Campus,

CEA Grenoble, 17 rue des Martyrs 38054 Grenoble, France, cyril.cayron@cea.fr

${ }^{3}$ Nuclear Materials Department, CEA Saclay, 91191 Gif-sur-Yvette, France, patrick.olier@cea.fr

${ }^{4}$ Nuclear Materials Department, CEA Saclay, 91191 Gif-sur-Yvette, France, joel.malaplate@cea.fr

${ }^{5}$ Nuclear Materials Department, CEA Saclay, 91191 Gif-sur-Yvette, France, mathilde.praud@cea.fr

${ }^{6}$ Laboratoire Léon Brillouin, CEA Saclay, 91191 Gif-sur-Yvette, France, marie-helene.mathon@cea.fr

${ }^{7}$ Nuclear Materials Department, CEA Saclay, 91191 Gif-sur-Yvette, France, didier.bossu@cea.fr

${ }^{8}$ Nuclear materials Department, CEA Saclay, 91191 Gif-sur-Yvette, France, elodie.rouesne@cea.fr

${ }^{9}$ Laboratory of Innovation for New Energy Technologies and Nanomaterials, PFNC, Minatec Campus,

CEA Grenoble, 17 rue des Martyrs 38054 Grenoble, France, alexandre.montani@cea.fr

${ }^{10}$ Mines ParisTech, CEMEF - Centre for Material Forming, CNRS UMR 7635, BP 207, 1 Rue Claude

Daunesse, 06904 Sophia Antipolis Cedex, France, roland.loge@mines-paristech.fr

${ }^{11}$ Nuclear Materials Department, CEA Saclay, 91191 Gif-sur-Yvette, France, yann.decarlan@cea.fr

Name $\quad$ : Louise Toualbi

Postal address : DEN-DANS/DMN/SRMA/LA2M Bat. 453 CEA Saclay 91191 Gif-sur-Yvette, France

Telephone number : : $33(0) 169081231$

Fax number : : $33(0) 169087130$

E-mail address : louise.toualbi@cea.fr 


\title{
Assessment of a new fabrication route for Fe-9Cr-1W ODS cladding tubes
}

\author{
L. Toualbi ${ }^{1,}$ C. Cayron ${ }^{2}$, P. Olier ${ }^{1}$, J. Malaplate ${ }^{1}$, M. Praud ${ }^{1}$, M.-H. Mathon ${ }^{3}$, D. Bossu' ${ }^{1}$, E. Rouesne ${ }^{1}$, A.
} Montani $^{2}$, R. Logé ${ }^{4}$, Y. de Carlan ${ }^{1}$

${ }^{1}$ CEA/DEN/DMN/SRMA, CEA Saclay, louise.toualbi@cea.fr

${ }^{2}$ CEA/DRT/LITEN, CEA Grenoble

${ }^{3}$ Laboratoire Léon Brillouin, CEA/Saclay

${ }^{4}$ Centre for Material Forming, MinesParistech, CNRS UMR 7635

\begin{abstract}
Oxide Dispersion Strengthened ferritic/martensitic steels are developed as future cladding materials for Generation IV Sodium-Cooled Fast Reactors. ODS alloys are elaborated by powder metallurgy, consolidated by hot extrusion and manufactured into tube cladding using cold rolling process.

ODS steels present low ductility and high hardness at room temperature which complicate their manufacturing. Cold working leads to the hardening of the tube which needs to be softened by heat treatment.
\end{abstract}

A new high temperature fabrication route performed on a Fe-9Cr-1W-Ti- $\mathrm{Y}_{2} \mathrm{O}_{3}-\mathrm{ODS}$ martensitic steel has been designed by following the hardness values, the morphological and crystallographic anisotropy and the nano-precipitation size evolution at each step of the fabrication route.

Observations show that phase transformation from ferrite $(\alpha)$ to austenite $(\gamma)$ is crucial to reduce the morphological and the crystallographic anisotropy induced by the manufacturing processes. The high temperature heat treatments permit to make the austenitic grain grow leading to an improvement of the cold workability.

Ultimate Tensile Strength values obtained in the hoop direction remain about $315 \mathrm{MPa}$ at $650^{\circ} \mathrm{C}$ which is slightly lower compared to other Fe-9Cr ODS tubes but the new microstructure could be more favorable for creep properties.

Keywords: ODS, phase transformation, cold rolling, texture measurements 


\section{Introduction}

Ferritic/martensitic oxide dispersion strengthened (ODS) alloys are candidates for cladding materials of Generation IV sodium nuclear reactors. These materials have to fulfill specific requirements such as limited deformations in service conditions. Ferritic/martensitic ODS materials present improved creep strength thanks to reinforcement by hard nano-sized particles (such as $\mathrm{Y}_{2} \mathrm{O}_{3}$ or $\mathrm{Y}_{2} \mathrm{Ti}_{2} \mathrm{O}_{7}$ ) and a high resistance to radiation-induced swelling due to the ferritic/martensitic matrix. The intermediate heat treatments performed during the fabrication are strongly linked to the chemical composition and have a crucial influence on the microstructural and mechanical properties of the final tube. Many studies are devoted to the development of ODS materials for nuclear applications [1-6]. The thermo-mechanical treatments have to be adjusted to determine a reliable fabrication route which allows the manufacturing of ODS cladding tubes with limited crystallographic and morphological anisotropy [6-9].

ODS cladding tubes are manufactured by following three main steps: 1) the mechanical alloying of the powders, 2) the consolidation of the material usually by hot extrusion and 3) the manufacturing by means of cold rolling passes punctuated by intermediate softening heat treatments. The aim of this work is to assess a high temperature fabrication route conducted on ODS martensitic steel with a chromium content around 9 wt.\% (nominal chemical composition Fe-9Cr-1W-0.1C-0.2Ti-0.3 $\mathrm{Y}_{2} \mathrm{O}_{3}$ ).

Hardness values, crystallographic and morphological anisotropy, nano-precipitation evolution and mechanical properties are the main characteristics studied in order to understand the microstructure evolution as a function of different thermo-mechanical treatments.

Fe-9Cr ODS materials are usually manufactured by using heat softening treatments at temperatures around $1050^{\circ} \mathrm{C}-1100^{\circ} \mathrm{C}$ [6-9]. In this study, high temperature annealing up to $1250^{\circ} \mathrm{C}$ are performed to induce an austenitic grain growth and to assess the impact of these heat treatments on the cladding tube microstructure and mechanical properties. A large austenitic grain size leads usually to a higher creep resistance and an easier hardenability. 


\section{Materials and experimental facilities}

\subsection{Materials}

A new grade of Fe-9Cr-1W ODS was developed at CEA. The alloy powders were obtained from Aubert \& Duval. Mechanical alloying was performed under hydrogen by Plansee: yttrium oxide powder (content of $0.3 \mathrm{wt}$.\%) was added by milling to the pre-alloyed matrix powders which contain $\mathrm{Fe}, \mathrm{Cr}, \mathrm{C}, \mathrm{W}$, Ti, etc.... (Table 1).

The mechanically alloyed powder was sealed in a soft steel can and hot extruded at a temperature of $1100^{\circ} \mathrm{C}$. This hot extrusion was performed with a hollow billet on an extrusion mandrel which allows calibrating the inner diameter. The cross section of the mandrel corresponds to the final expected inner diameter of the mother tube. The diameters of extrusion die and mandrel were $23 \mathrm{~mm}$ and $13.5 \mathrm{~mm}$, respectively. After chemical dissolution of the soft steel can, mother tubes with $19 \mathrm{~mm}$ outer diameter and $2 \mathrm{~mm}$ wall thickness are obtained.

Cladding tubes are manufactured by HPTR pilger type equipment at CEA/SRMA (Fig. 1). This forming process allows reducing simultaneously the thickness and the outer diameter of the tube. At room temperature the ODS materials are too hard to be manufactured by cold rolling without softening. This process induces a hardness increase leading to possible damage (cracks). Based on previous studies a hardness value below $400 \mathrm{H}_{\mathrm{V} 1}$ is needed to avoid damage during manufacturing [8]. The rolling passes are punctuated by intermediate heat treatments allowing a reduction of the material hardness. Fabrication routes are determined to reach the final geometry of the cladding tubes: $10.73 \mathrm{~mm}$ outer diameter and $500 \mu \mathrm{m}$ wall thickness.

Cold rolling parameters depend on the chemical composition of the ODS material. Preliminary studies are needed to get appropriate intermediate heat treatments and cross-section reduction ratio for each ODS grade manufactured.

Figure 1, Table 1

\subsection{Experimental facilities}

Samples were taken at different steps of the fabrication route in order to observe the hardness change in the course of cladding tube manufacturing. Microscopic observations and Vickers hardness measurements using $1 \mathrm{~kg}$ loading were performed on longitudinal and transverse sections relative to the 
rolling direction.

Phase transformation temperatures of ODS martensitic steel were investigated by using samples taken from a hot extruded bar with the same nominal chemical composition. Dilatometric measurements were performed on a connecting rod dilatometer DT1000.

The evolution of the grains morphology was investigated in both longitudinal and transverse directions by EBSD (Electron BackScatter Diffraction). The EBSD patterns were acquired with the Channel 5 EBSD software (HKL Technology) on a LEO1530 FEG-SEM (Field Emission Gun Scanning Electron Microscope). All samples were prepared for EBSD measurements by mechanical grinding followed by a soft vibratory polishing with non-crystalline colloidal silica on Vibromet 2 (Buehler).

The local EBSD texture is shown by drawing the experimental inverse pole figure in the extrusion or in the rolling direction and the corresponding multiples of uniform density (MUD) which represent the strength of the pole densities. The highest density $\mathrm{MUD}_{\max }$ around the main pole (here $<110>$ ) is a good semi-quantitative parameter of the texture intensity and can be used to compare the effect of the thermomechanical treatments on the $<110>$ fiber texture. EBSD scans were drawn using disorientation criteria above $10^{\circ}$ to determine the grain boundaries.

TEM observations were performed on ODS cladding tube and ODS hot extruded bar samples. Specimens were ground to a thickness of about $100 \mu \mathrm{m}$. 3mm diameter TEM punched discs were electropolished at $-10^{\circ} \mathrm{C}$ in a specific solution (10\% perchloric acid and $90 \%$ ethanol). TEM observations were carried out on a 2010FEG JEOL at 200kV.

Small Angle Neutron Scattering measurements were performed on ODS cladding tube and ODS hot extruded bar samples in the PAXY instrument of the Laboratoire Léon Brillouin. Two different configurations of wavelength $(\lambda)$ and sample-to-detector distance have been used $(0.6 \mathrm{~nm} / 2 \mathrm{~m}$ and $0.9 \mathrm{~nm} / 5 \mathrm{~m})$ covering a maximal scattering vector $(\mathbf{q})$ range from 0.08 to $1.6 \mathrm{~nm}^{-1}(\mathrm{q}=4 \pi \sin \theta / \lambda$ where $2 \theta$ is the scattering angle). For ferromagnetic materials, the neutron scattering cross-section is composed of a nuclear contribution and a magnetic one. Measurements were made at room temperature under a saturate magnetic field of 1.7 Tesla perpendicular to the incident neutron beam direction [10-11].

The analysis method is reported in detail [11]. Briefly, the SANS data were fitted assuming one or two Gaussian size distributions of spherical particles. With the assumption that the objects are not ferromagnetic, the analysis of the magnetic scattered intensity allows to determine their volume fraction 
without chemical composition information. Indeed, the magnetic contrast depends only on the mean magnetic moment of the matrix atoms.

This method was used for the data obtained on hot extruded bars for which the magnetic contribution could be isolated. For the cladding tube, however, the scattered intensity shows a relatively large morphological anisotropy. Without magnetic field, the intensity is consistent with slightly elongated particles oriented parallel to the tube axis. In this case, it is impossible to separate the effects of shape anisotropy and of the magnetic scattering. Therefore, measurements were taken without magnetic field and the signal considered isotropic which induces an averaging effect on the size of objects. In order to determine the volume fraction, both the magnetic and nuclear contrasts have to be calculated. Some assumptions concerning the chemical composition of the oxides should be done.

Tensile tests in the transverse direction were carried out on the ODS-9Cr cladding tube by means of ring tensile specimens in order to evaluate the cladding resistance in the hoop direction which is the main load direction in service conditions. Ultimate Tensile Strength values were determined in the temperature range $20-700^{\circ} \mathrm{C}$ and compared to equivalent tensile tests conducted on ODS-9Cr cladding tube produced by JAEA [8], on ODS-9Cr cladding tube manufactured by a collaboration between JNC and CEA [12] and on conventional 9Cr steel (P92) [13].

\section{Elaboration of the 9Cr-ODS martensitic cladding tube}

\subsection{Phase transformation}

9Cr-ODS martensitic steels present a ferrite to austenite phase transformation during heating. Dilatometric measurements conducted on the 9Cr-ODS martensitic steel give the characteristic temperatures at starting and finishing phase transformation during heating. The temperatures obtained (around $850^{\circ} \mathrm{C}$ for starting point $\mathrm{Ac}_{1}$ and $900^{\circ} \mathrm{C}$ for finishing point $\mathrm{Ac}_{3}$ ) are similar to phase transformation temperatures of conventional martensitic steel and of other 9Cr-ODS materials [14-16].

A Continuous Cooling Transformation (CCT) diagram for 9Cr-ODS martensitic steels is drawn from the thermal expansion data (Fig. 2). According to the phase transformation temperatures previously determined, samples are normalized at $1050^{\circ} \mathrm{C}$ for 20 minutes and cooled to room temperature at varying cooling rates from $0.05^{\circ} \mathrm{C} / \mathrm{s}$ to $100^{\circ} \mathrm{C} / \mathrm{s}$. Vickers hardness measurements and corresponding optical 
observations are performed for each cooling rate. The critical cooling rate to obtain a fully martensitic structure is of around $1^{\circ} \mathrm{C} / \mathrm{s}$. This value implies that hardening by quenching and getting a fully martensitic structure is possible only for the thin products.

Figure 2

\subsection{Fabrication route}

According to the CCT diagram (Fig. 2), heat treatments can control the metallurgical state of the 9CrODS martensitic tube. To avoid any damage during cold working the hardness of the mother tube has to be low enough: cold rolling is performed on the softened ferritic structure induced by slow cooling rate. After hot extrusion, the $9 \mathrm{Cr}$-ODS mother tube is homogenized at $1250^{\circ} \mathrm{C}$ for $30 \mathrm{~min}$ and cooled to room temperature with a slow cooling rate of $0.03^{\circ} \mathrm{C} / \mathrm{s}$. The hardness value of $250 \mathrm{H}_{\mathrm{V} 1}$ indicates a ferritic structure which can easily be cold worked.

Fabrication route is a combination of rolling passes and intermediate heat treatments. Based on previous studies the cross-section reduction ratio for each pass is limited to approximately $20 \%-25 \%$ [12]. Hardness evolution allows adjusting the fabrication parameters in the course of cladding manufacturing process. The ferrite to austenite phase transformation allows releasing the internal stresses induced by cold working: intermediate heat treatments have to reach the austenite phase. As point out by Sandim et al., heat treatments below this phase transformation do not allow to recrystallize the material and to release the internal stresses [15]. After 3 passes the cold rolled tube is heat treated at $1200^{\circ} \mathrm{C}$ for $1 \mathrm{~h}$ and slowly cooled in order to induce the softened ferritic structure. This intermediate annealing causes a significant hardness reduction of about $80 \mathrm{H}_{\mathrm{V} 1}$ which proves its efficiency. Figure 3 shows the hardness evolution in the course of cladding manufacturing process.

After 9 rolling passes the final dimension of the cladding tube are $10.73 \mathrm{~mm}$ outer diameter and $500 \mu \mathrm{m}$ wall thickness. A final tempering treatment is performed at $750^{\circ} \mathrm{C}$ for $1 \mathrm{~h}$ followed by an air quench with a cooling rate of $1^{\circ} \mathrm{C} / \mathrm{s}$. Hardness measurement gives a value of $300 \mathrm{H}_{\mathrm{V} 1}$ for this ferritic structure.

Figure 3 


\section{Microstructure}

In order to investigate the impact of the heat treatments on the grain morphology, optical observations are performed on longitudinal and transverse cross-sections of samples taken from the 9Cr-ODS tube at different steps of the fabrication route. Samples are polished and chemically etched with Villela reagent but it is difficult to highlight the grain boundaries. These observations are not accurate enough to fully understand the microstructure evolution during the manufacturing. Different experimental techniques are then carried out on cladding tube samples.

\subsection{EBSD characterization}

In order to evaluate the effect of high temperature heat treatment on the austenite grain growth, EBSD scans obtained on a transversal section of the mother tube annealed at $1050^{\circ} \mathrm{C}$ and $1250^{\circ} \mathrm{C}$ respectively for 30 minutes are compared in figure 4 . After heat treatment at $1050^{\circ} \mathrm{C}$ the mean grain size remains small (around $1 \mu \mathrm{m}$ as shown in Fig. 4.a.) with an isotropic microstructure. On the contrary when the mother tube is heated at higher temperature the mean grain size became much larger (around 5-10 $\mu$ m) which allows to quantify the efficiency of this annealing to make the austenitic grains grow. This highest annealing temperature is chosen to soften the mother tube after hot extrusion. Experimental inverse pole figures obtained in the extrusion direction are presented. In both cases, the texture intensity induced by the hot extrusion process is significantly reduced by the phase transformation, since the highest density $\mathrm{MUD}_{\max }$ around the main pole $<110>$ is equal to 2 for the mother tube annealed at $1050^{\circ} \mathrm{C}$ or 3 for the mother tube annealed at $1250^{\circ} \mathrm{C}$ (Fig. 4). On a fully ferritic material (Fe-14Cr ODS material) after hot extrusion, the $\mathrm{MUD}_{\max }$ around the main pole $<110>$ is close to 30 .

After 3 rolling passes the hardness measurements give a value of $300 \mathrm{H}_{\mathrm{V} 1}$. An intermediate heat treatment at $1200^{\circ} \mathrm{C}$ for $1 \mathrm{~h}$ is performed to soften the raw tube. The comparison of EBSD scans of figures 5 and 6 reveals the impact of this annealing on the grain morphology. Sample taken from the raw tube after 3 rolling passes presents slightly elongated grains on the longitudinal cross-section sample (around 3-5 $\mu \mathrm{m}$ thick and 5-10 $\mu \mathrm{m}$ long). The crystallographic texture remains light: the highest density MUD $_{\max }$ around 
the $<110>$ pole is equal to 2 (Fig. 5). After the intermediate heat treatment the elongated grain shape is changed into an equiaxial grain shape which proves the efficiency of the phase transformation to reduce the morphological anisotropy introduced by the rolling process (Fig. 6). The grain size remains about 7$15 \mu m$ which indicates that the hardening introduced by cold working does not enhance the austenitic grain growth.

After 9 rolling passes with a reduction ratio of about $20 \%$ per pass, hardness measurements give a value around $300 \mathrm{H}_{\mathrm{V} 1}$. The final geometry of the cladding tubes is reached. In order to have high mechanical properties it was chosen to keep the hardening introduced by the manufacturing process and to perform a tempering as the final heat treatment $\left(750^{\circ} \mathrm{C}\right.$ for $\left.1 \mathrm{~h}\right)$. EBSD scans of the figure 7 show fine and elongated grains in the longitudinal direction $(0.1-1 \mu \mathrm{m}$ thick and $10-20 \mu \mathrm{m}$ long). The measurement of the texture intensity gives an increased $\mathrm{MUD}_{\max }$ value of 8 (Fig. 7), which is the highest texture detected all along the fabrication route.

Figures 4, 5,6 and 7

\subsection{TEM observations}

Transmission electron microscopy was used to study the grain size and the nano-precipitation evolution during the fabrication route. TEM observations were not carried out on mother tube after hot extrusion but on a Fe-9Cr-1W ODS hot extruded bar manufactured with similar conditions. The TEM observations and SANS measurements (see next paragraph) permit calculating the mean size of nanoprecipitate. The density of these strengthening nano-precipitates in 9Cr-ODS bar is calculated around $2 \times 10^{22} \mathrm{~m}^{-3}$ with an average radius of $2 \mathrm{~nm}$.

TEM observations performed on longitudinal section of cladding tube samples reveal an elongated grain structure (less than $1 \mu \mathrm{m}$ thick and a few $\mu \mathrm{m}$ long). The mean radius of strengthening precipitates is measured about $4.5 \mathrm{~nm}$ which is larger than observed on 9Cr-ODS extruded bars. The number density measured in 9Cr-ODS cladding tube is around $10^{22} \mathrm{~m}^{-3}$ (Fig. 8).

Figure 8 


\subsection{SANS measurements}

Small Angle Neutron Scattering (SANS) measurements are performed on the 9Cr-ODS cladding tube, on a Fe-9Cr-1W ODS hot extruded bar and also on a Fe-14Cr-1W ODS hot extruded bar. The mechanical alloying and the hot extrusion are performed under the same conditions for all these materials. With the assumption that the microstructure of the 9Cr-ODS hot extruded bar is similar than the one of the 9CrODS mother tube before annealing, we can follow the evolution of the particles size during the manufacturing. To complete this study, the microstructure evolution is compared with the one observed on ferritic hot extruded bars which do not present any phase transformation.

$S_{D}$ represents the size distribution weighted by the volume fraction $f_{P}$ (Fig. 9). Areas under the curves correspond to the total volume fraction of particles detected by SANS. For the cladding tube, SANS results are analyzed under the assumption that the nano-precipitates are YTiO clusters.

For the 14Cr-ODS hot extruded bar, a bimodal population of nano-precipitates is detected with a small mean radius $\mathrm{R}_{\mathrm{m} 1}$ about $1.4 \mathrm{~nm}$ and a larger mean radius $\mathrm{R}_{\mathrm{m} 2}$ about $3.9 \mathrm{~nm}$. The volume fraction of each population is respectively $1.33 \%$ and $0.25 \%$ which means that most of the nano-precipitates have a size of about $1.4 \mathrm{~nm}$ of radius.

For the 9Cr-ODS samples, in both cases SANS technique detects a bimodal population also characterized by a small mean radius $\mathrm{R}_{\mathrm{m} 1}$ about $1.8 \mathrm{~nm}$ for the hot extruded bar and about $1 \mathrm{~nm}$ for the cladding tube and a larger mean radius $\mathrm{R}_{\mathrm{m} 2}$ about $5 \mathrm{~nm}$ for both samples. The main difference between the hot extruded bar and the cladding tube concerns the volume fractions for each population. In the hot extruded bar the volume fraction is $1.2 \%$ for the smallest precipitates and $0.5 \%$ for the coarse one. Most of the nano-particles detected in 9Cr-ODS hot extruded bar have a radius of about $2 \mathrm{~nm}$ or less. On the contrary, in the cladding tube the volume fraction of the largest precipitates is much more important $(1.53 \%)$ than the volume fraction of the smallest one $(0.14 \%)$. Most of the nano-precipitates detected in cladding tube are characterized by a larger radius of about $5 \mathrm{~nm}$. These results indicate that the number of larger particles is much bigger in the cladding tube than in the hot extruded bar.

Figure 9 


\subsection{Mechanical properties}

Ultimate Tensile Strength of three different 9Cr-ODS cladding tubes are compared to that of a conventional 9Cr steel, P92 (Fig. 10). UTS values decrease with increasing temperature for all tested grades. All 9Cr-ODS cladding tubes exhibit higher strength in the transverse direction than the conventional 9Cr steel. The Fe-9Cr-2W-0.35 $\mathrm{Y}_{2} \mathrm{O}_{3}$-ODS cladding tube manufactured at JAEA shows the highest UTS values at all tested temperatures with a strength value around $500 \mathrm{MPa}$ at $650^{\circ} \mathrm{C}$. The $\mathrm{Fe}-9 \mathrm{Cr}-$ $2 \mathrm{~W}-0.25 \mathrm{Y}_{2} \mathrm{O}_{3}$-ODS JNC/CEA cladding tube and the Fe-9Cr- $1 \mathrm{~W}-0.3 \mathrm{Y}_{2} \mathrm{O}_{3}$-ODS cladding tube elaborated in this study present strength values of about $400 \mathrm{MPa}$ and $315 \mathrm{MPa}$ respectively at $650^{\circ} \mathrm{C}$.

Figure 10

\section{Discussion}

The aim of this study is to assess a new fabrication route characterized by high temperature heat treatments and increased grain sizes compared to conventional fabrication route of ODS cladding tubes. This new fabrication route has permitted to improve the cold workability.

\subsection{Microstructure evolution}

It has to be noticed that high temperature austenitizing is efficient to break down the elongated grain structure induced by rolling passes and to change the cladding structure into an equiaxial grain structure (Fig. 5 and 6). The morphological texture introduced by the manufacturing processes is significantly reduced due to the austenite to ferrite phase transformation. The austenitic grain growth remains moderate with a size around $10 \mu \mathrm{m}$ even after a heat treatment at $1250^{\circ} \mathrm{C}$ for 30 minutes. On conventional martensitic steels a much bigger grain size about few hundreds $\mu$ m would be expected.

Concerning the nano-precipitation, Small Angle Neutron Scattering results show that the main difference between ferritic and martensitic ODS materials is that most of the particles detected in ferritic hot extruded bar present a mean radius around $1 \mathrm{~nm}$, whereas most of the particles detected in martensitic 
hot extruded bar have a size twice bigger (radius around $2 \mathrm{~nm}$ ). These results could be due to a difference of the coherency between the nano-phases and the matrix. In the 14Cr-ODS bar, nano-phases are coherent with the matrix [17] but in the 9Cr-ODS material, because of the $(\alpha)$ to $(\gamma)$ phase transformation, this coherency is probably lost as mentioned by Yamamoto [18] and the coarsening resistance is deteriorated [17-19]. No coherency of the nano-particles with the matrix was observed. The mean radius of the nanophases is close to $5 \mathrm{~nm}$ after different heat treatments up to $1250^{\circ} \mathrm{C}$. On the contrary, the mean size of the nano-precipitates detected in the 14Cr-ODS bar are close to $2.5 \mathrm{~nm}$ of radius, even after a heat treatment at $1400^{\circ} \mathrm{C}$ for $1 \mathrm{~h}$. Since this annealing does not induce a recrystallization or a phase transformation, the nanophases remain coherent with the matrix and keep a good coarsening resistance [20].

SANS measurements also permit to study the nano-precipitation size evolution during the fabrication route since the hot extruded bar is comparable to the mother tube before annealing. A bimodal population is detected in both samples, but the volumic fraction of nano-precipitates with a small radius (around $1 \mathrm{~nm}$ ) is much more important in the extruded bar sample than in the cladding tube. The high temperature heat treatment leads to an increase of the particles mean size. Most of the nano-precipitates detected in the cladding tube present a mean radius around 5nm. The impact on the creep resistance of the nano-precipitates growth from $2 \mathrm{~nm}$ to $5 \mathrm{~nm}$ of radius during manufacturing has to be studied.

\subsection{Thermo-mechanical optimizations}

First mechanical characterizations are obtained. The results already indicate rather good mechanical properties. If needed, the following optimizations are realizable to improve the mechanical properties.

In this study, the cladding tube presents a work hardened tempered ferritic structure. The critical cooling rate allowing the formation of a fully martensitic structure is impacted by the grain growth [21]. Having a martensitic structure will be easier on the high temperature annealed tube. An additional improvement could easily be performed by carrying out an austenitizing following by a quenching and a tempering as final heat treatment in order to obtain a tempered martensitic structure. A work hardened 
martensitic structure can also be envisaged as alternative solution to increase the mechanical strength of the cladding tube.

Another way to optimize the fabrication route is to induce the grain growth without performing annealing at high temperature. In some cases, several thermal cycles performed between austenitic and ferritic domains can lead to an increase of the grain size [22]. A slow cooling rate permits to increase the grain size within the ferritic phase. The annealing temperature remains below $1000^{\circ} \mathrm{C}$ which limits the coalescence of the nano-precipitates. Such specific heat treatments have been performed with success on 9Cr-ODS plates [22] and could be tested on 9Cr-ODS tubes.

The mechanically pertinence of all these possibilities, including the cladding tube obtained through the fabrication route described in this study, have to be assessed with creep tests to see if the expected benefits are confirmed.

\section{Conclusion}

The high temperature fabrication route proposed is efficient to ensure a safe manufacturing of 9Cr-ODS cladding tube. From the beginning of the fabrication route to the final tube the hardness values remains far below the critical value of $400 \mathrm{H}_{\mathrm{V} 1}$. The role of the $\alpha / \gamma$ phase transformation is crucial to reduce the morphological and the crystallographic anisotropy induced by the manufacturing processes. TEM observations and SANS measurements indicate that most of the nano-precipitates detected in the cladding tube have a mean radius of about $5 \mathrm{~nm}$. The number density calculated is around $10^{22} \mathrm{~m}^{-3}$. Ultimate Tensile Strength values obtained in the hoop direction are higher than on conventional martensitic steel (315MPa at $\left.650^{\circ} \mathrm{C}\right)$. The creep resistance, which is impacted by both the austenitic grain growth and the precipitates size increase, has to be determined and if necessary further optimizations are possible in order to improve the mechanical properties. 


\section{Acknowledgments}

The authors would like to inform that this work was conducted thanks to CEA-EdF-AREVA collaboration.

We thank Denis Venet (CEA Grenoble) for the sample preparation needed for the EBSD characterizations and Jean-Luc Béchade for the fruitful discussions on the EBSD textures. 


\section{References}

[1] Y. de Carlan, J.-L. Béchade, P. Dubuisson, J.-L. Seran, P. Billot, A. Bougault, T. Cozzika, S. Doriot, D. Hamon, J. Henry, M. Ratti, N. Lochet, D. Nunes, P. Olier, T. Leblond, M.-H. Mathon, CEA developments of new ferritic ODS alloys for nuclear applications, Journal of Nuclear Materials 386-388 (2009) 430-432

[2] R. Lindau, A. Möslang, M. Rieth, M. Klimiankou, E. Materna-Morris, A. Alamo, A.-A. F. Tavassoli, C. Cayron, A.-M. Lancha, P. Fernandez, N. Baluc, R. Schäublin, E. Diegele, G. Filacchioni, J.W. Rensmanh, B.v.d. Schaaf, E. Lucon, W. Dietz, Present development status of EUROFER and ODS EUROFER for application in blanket concepts, Fusion Engineering and Design 75-79 (2005) 989-996

[3] A. Kimura, H.S. Cho, N. Toda, R. Kasada, K. Yutani, H. Kishimoto, N. Iwata, S. Ukai, M. Fujiwara, High burn up fuel cladding materials $R \& D$ for advanced nuclear systems - Nano-sized oxide dispersion strengthening steels, Journal of Nuclear Science and Technology, Vol. $44 \mathrm{~N}^{\circ} 3$ (2007) 323-328

[4] A.A. Nikitina, V.S. Ageev, A.P. Chukanov, V.V. Tselev, N.P. Porezanov, O.A. Kruglov, $R \& D$ of ferritic-martensitic steel EP450 ODS for fuel pin claddings of prospective fast reactors, Proceedings of DIANA I workshop "Dispersion Strengthened steels for advanced nuclear applications”, Aussois (France) April 4-8, 2011, submitted to Journal of Nuclear Materials

[5] J. Alinger, G.R. Odette and D.T. Hoelzer, The development and stability of Y-Ti-O nanoclusters in mechanically alloyed Fe-Cr based ferritic alloys, Journal of Nuclear Materials Vol. 329-333 (2004), 382-386

[6] P. Dubuisson, Y. de Carlan, V. Garat, M. Blat, ODS Ferritic / Martensitic alloys for Sodium Fast Reactor fuel pin cladding, Proceedings of DIANA I workshop "Dispersion Strengthened steels for advanced nuclear applications”, Aussois (France) April 4-8, 2011, submitted to Journal of Nuclear Materials 
[7] S. Ukai, M. Fujiwara, Perspective of ODS alloys application in nuclear environments, Journal of Nuclear Materials 307-311 (2002) 749-757

[8] M. Inoue, T. Kaito, S. Ohtsuka, Research and development of oxide dispersion strengthened ferritic steels for sodium cooled fast breeder reactor fuels, Cargèse, Sept. 24 - Oct. 6, 2007

[9] S. Ukai, S. Ohnuki, S. Hayashi, T. Kaito, M. Inoue, A. Kimura, T. Fujisawa, T. Okuda, F. Abe, Super ODS steels $R \& D$ for fuel cladding of next generation nuclear systems, Proceedings of ICAPP '09, Paper 9232, Tokyo, Japan, May 10-14, 2009

[10] M.H. Mathon, Y. de Carlan, G. Geoffroy, X. Averty, A. Alamo, C.H. de Novion, Journal of Nuclear Materials 312 (2003) 236-248

[11] M.H. Mathon, M. Perrut, S.Y. Zhong, Y. de Carlan, Small Angle Neutron Scattering Study of martensitic/ferritic ODS alloys, Proceedings of DIANA I workshop "Dispersion Strengthened steels for advanced nuclear applications”, Aussois (France) April 4-8, 2011, submitted to Journal of Nuclear Materials

[12] S. Ukai, T. Narita, A. Alamo, P. Parmentier, Tube manufacturing trials by different routes in 9CrW-ODS martensitic steels, Journal of Nuclear Materials 329-333 (2004) 356-361

[13] D. Richardot, J.C. Vaillant, A. Arbab, W. Bendick, Vallourec \& Mannesmann Tubes, The T92/P92 Book, 2000

[14] S. Ukai, S. Mizuta, M. Fujiwara, T. Okuda and T. Kobayashi, Development of 9Cr-ODS Martensitic Steel Claddings for Fuel Pins by means of Ferrite to Austenite Phase Transformation, Journal of Nuclear Science and Technology, Vol. 39, No. 7, p. 778-788 (July 2002) 
[15] H.R.Z. Sandim, R.A. Renzetti, A.F. Padilha, D. Raabe, M. Klimenkov, R. Lindau, A. Möslang, Annealing behavior of ferritic-martensitic 9\%Cr-ODS-Eurofer steel, Materials Science and Engineering A 527 (2010) 3602-3608

[16] C. Cayron, E. Rath, I. Chu, S. Launois, Microstructural evolution of $\mathrm{Y}_{2} \mathrm{O}_{3}$ and $\mathrm{MgAl}_{2} \mathrm{O}_{4} \mathrm{ODS}$ EUROFER steels during their elaboration by mechanical milling and hot isostatic pressing, Journal of Nuclear Materials 335 (2004) 83-102

[17] J. Ribis, Y. de Carlan, Interfacial strained structure and orientation relationship of the nano-sized oxide particles in Oxide Dispersion Strengthened materials, Acta Materialia, DOI: 10.1016/j.actamat.2011.09.042

[18] M. Yamamoto, S. Ukai, S. Hayashi, T. Kaito, S. Ohtsuka, Reverse Phase Transformation from $\alpha$ to $\gamma$ in 9Cr-ODS Ferritic Steels, Journal of Nuclear Materials (2010)

[19] Y. Yazawa, T. Furuhara, T. Maki, Effect of matrix recrystallization on morphology, crystallography and coarsening behavior of vanadium carbide in austenite, Acta Materialia 52 (2004) 3727-3736

[20] S.Y. Zhong, J. Ribis, V. Klosek, Y. de Carlan, N. Lochet, V. Ji, M.H. Mathon, Study of distribution of nano particles in ferritic steels strengthened by dispersion of oxides, Proceedings of DIANA I workshop "Dispersion Strengthened steels for advanced nuclear applications”, Aussois (France) April 4-8, 2011, submitted to Journal of Nuclear Materials

[21] J.-C. Brachet, V. Lambard, A. Alamo, Studies of Phase Transformations Occurring in Conventional, Low Activation (LA) and Oxide Dispersion Strengthened (ODS) 7-11\%Cr-(Mo, W, $V, N b, T a)$ Martensitic Steels, The Japan Institute of Metals Proceedings 1999 - Solid-Solid Phase Transformations I and II, vol.12, pp.1609-1612

[22] V. Lambard et al., United States Patent, Method of Manufacturing a Ferritic-Martensitic, Oxide Dispersion Strengthened Alloy, Patent No. US 6,974,506 B2, Date of Patent Dec. 13, 2005 
Table 1

Chemical composition of martensitic mother tube (mass\%)

\begin{tabular}{cccccccccccc}
\hline \% massic & Fe & $\mathbf{C r}$ & $\mathbf{W}$ & $\mathbf{T i}$ & $\mathbf{Y}$ & $\mathbf{S i}$ & $\mathbf{N i}$ & $\mathbf{M n}$ & $\mathbf{C}$ & $\mathbf{N}$ & $\mathbf{O}$ \\
\hline Martensitic grade & bal. & 9.5 & 1.1 & 0.3 & 0.2 & 0.2 & 0.3 & 0.3 & 0.11 & 0.04 & 0.13 \\
\hline
\end{tabular}


Figure captions

Figure 1: HPTR pilger type equipment

Figure 2: Continuous Cooling Transformation diagram and corresponding optical micrographs (longitudinal cross-section) of 9Cr-ODS martensitic steel

Figure 3: Hardness evolution in the course of cladding manufacturing process

Figure 4: EBSD scans and related experimental inverse pole figure obtained on the transverse cross-section of mother tube after hot extrusion and annealing at a) $1050^{\circ} \mathrm{C}$ for $30 \mathrm{~min}$ and b) $1250^{\circ} \mathrm{C}$ for $30 \mathrm{~min}$

Figure 5: EBSD scans and related experimental inverse pole figure obtained on the a) transverse and b) longitudinal cross-sections of raw tube after 3 rolling passes

Figure 6: EBSD scans and related experimental inverse pole figure obtained on the a) transverse and b) longitudinal cross-sections of raw tube after 3 rolling passes and intermediate heat treatment at $1200^{\circ} \mathrm{C}$ for $1 \mathrm{~h}$

Figure 7: EBSD scans and related experimental inverse pole figure obtained on the a) transverse and b) longitudinal cross-sections of cladding tube after final heat treatment

Figure 8: Transmission electron micrographs of 9Cr-ODS martensitic cladding tube after final heat treatment

Figure 9: SANS measurements on Fe-14Cr-1W extruded bar (dotted line) Fe-9Cr-1W extruded bar (dashed line) and cladding tube after final heat treatment (continuous line)

Figure 10: Comparison of ultimate tensile strength between a conventional 9Cr steel P92 (dashed line) and three different grades of 9Cr-ODS martensitic steels: 9Cr-2W ODS cladding tube manufactured at JAEA (filled circles), 9Cr-2W ODS cladding tube elaborated through a JNC/CEA collaboration (empty circles) and 9Cr-1W cladding tube manufactured by a high temperature fabrication route at CEA (filled squares). 
Figure 1

HPTR pilger type equipment

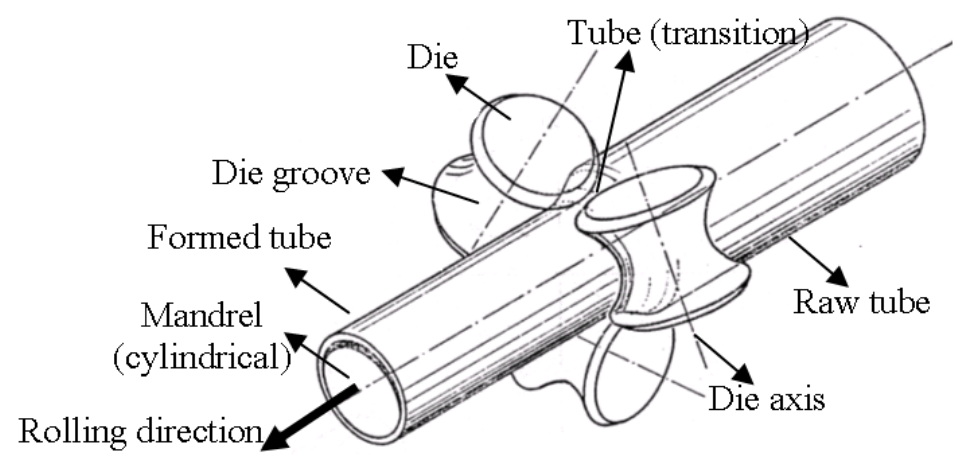


Figure 2

Continuous Cooling Transformation diagram and corresponding optical micrographs (longitudinal crosssection) of 9Cr-ODS martensitic steel

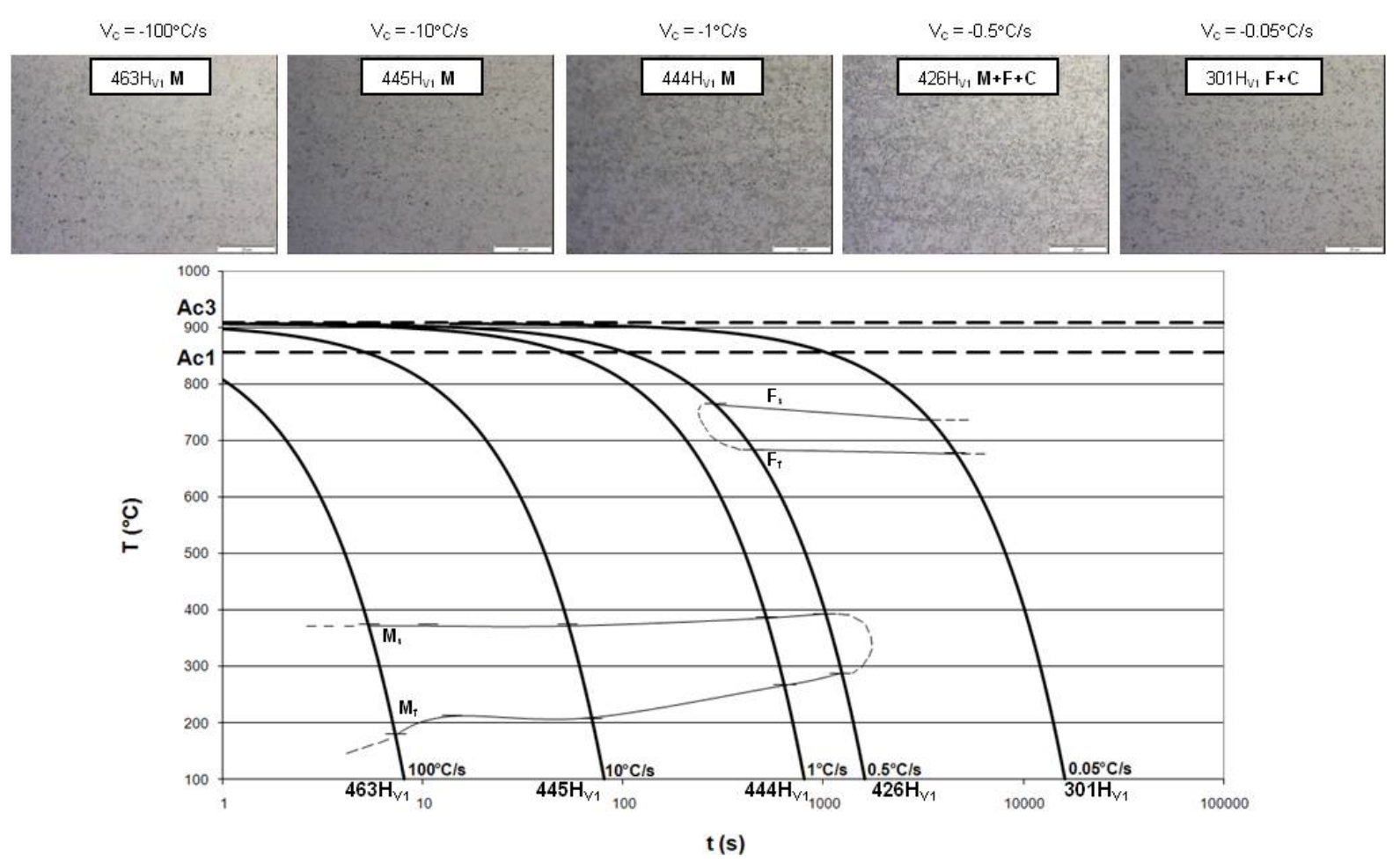

Corresponding Author name: Toualbi

Column width: 2 
Figure 3

Hardness evolution in the course of cladding manufacturing process

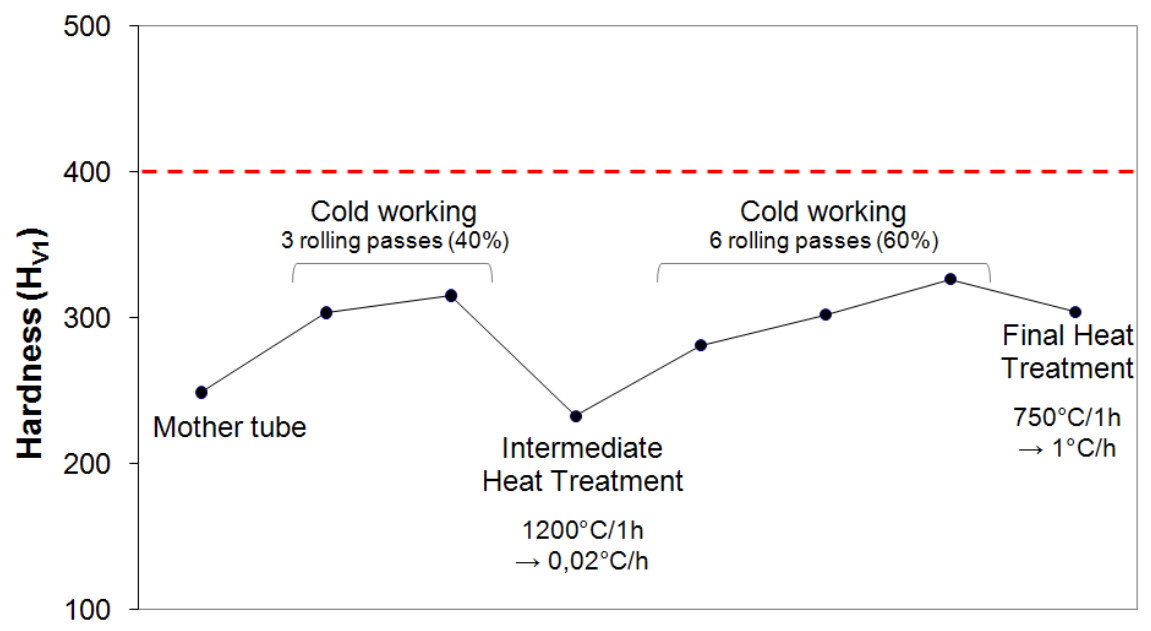

Corresponding Author name: Toualbi

Column width: 1 
Figure 4

EBSD scans and related experimental inverse pole figure obtained on the transverse cross-section of mother tube after hot extrusion and annealing at a) $1050^{\circ} \mathrm{C}$ for $30 \mathrm{~min}$ and b) $1250^{\circ} \mathrm{C}$ for $30 \mathrm{~min}$

a)

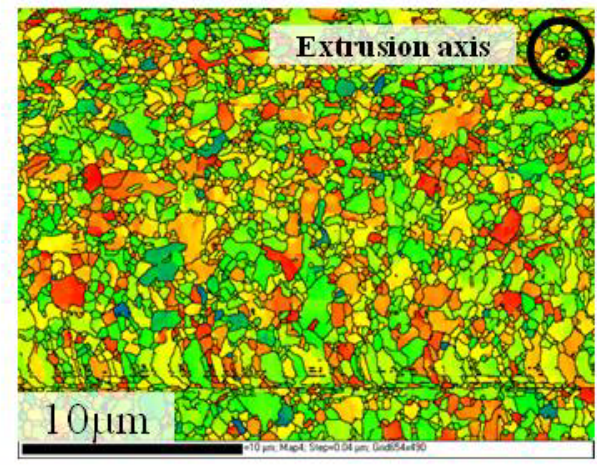

Color code of EBSD scan: angle between $\langle 110\rangle$ and $z$ axis (extrusion axis) from $0^{\circ}$ ( $\mathrm{red}$ ) to $50^{\circ}$ (blue)
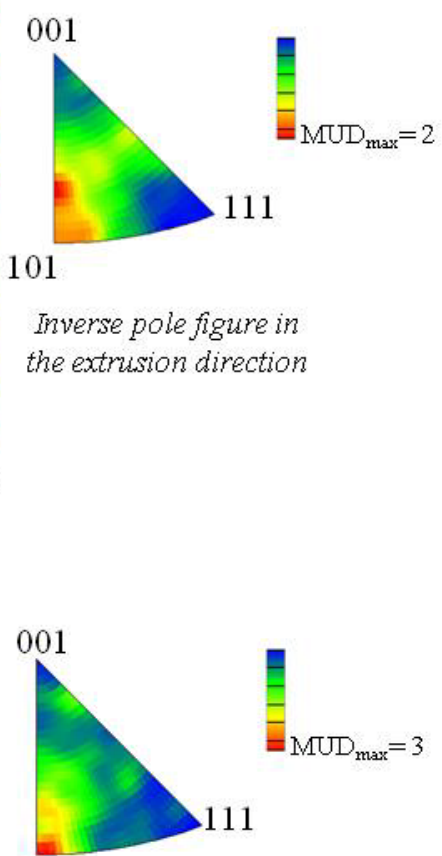

101

Inverse pole figure in the extrusion direction

Corresponding Author name: Toualbi

Column width: 2 
Figure 5

EBSD scans and related experimental inverse pole figure obtained on the a) transverse and b) longitudinal cross-sections of raw tube after 3 rolling passes

a)

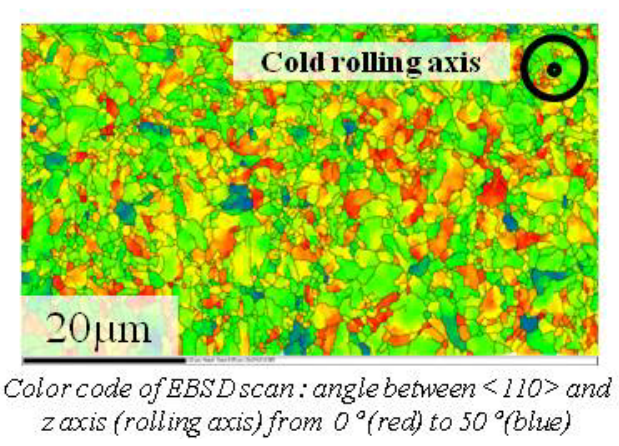

b)

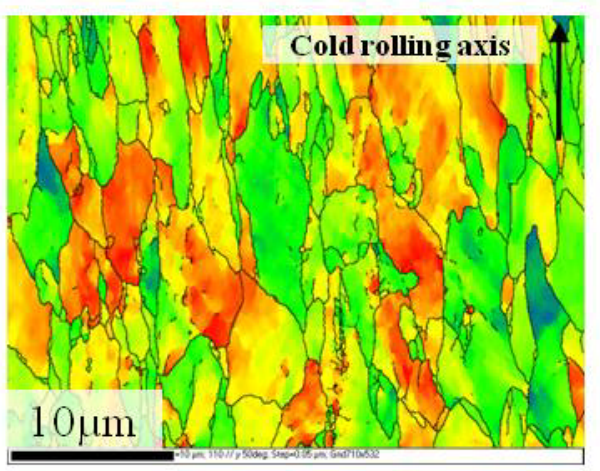

Color code of EBSD scan: angle between $<110\rangle$ and $x$ or $y$ axis (radial direction of the tube) from $0^{\circ}$ (red) to $50^{\circ}$ (blue)
001
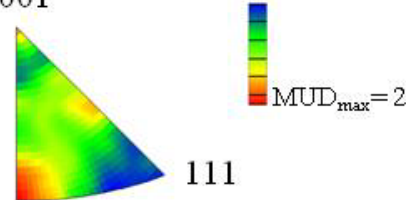

111

101

Inverse pole figure in

the rolling direction

Corresponding Author name: Toualbi

Column width: 2 
Figure 6

EBSD scans and related experimental inverse pole figure obtained on the a) transverse and b) longitudinal cross-sections of raw tube after 3 rolling passes and intermediate heat treatment at $1200^{\circ} \mathrm{C}$ for $1 \mathrm{~h}$

a)

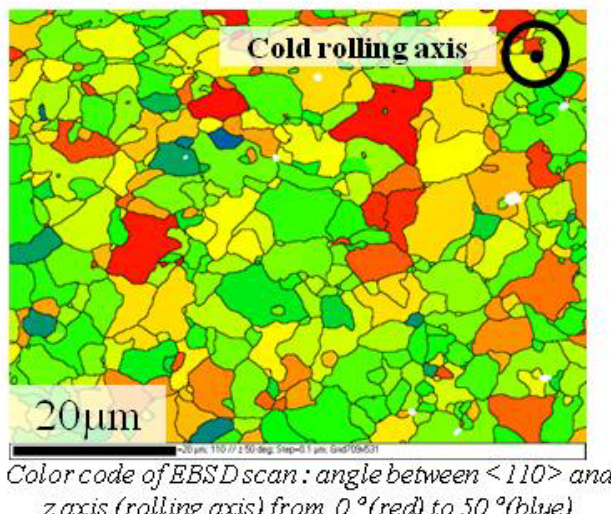

001

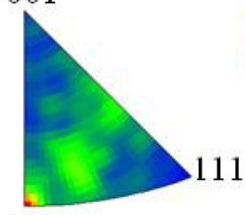

101

Inverse pole figure in

the rolling direction

b)

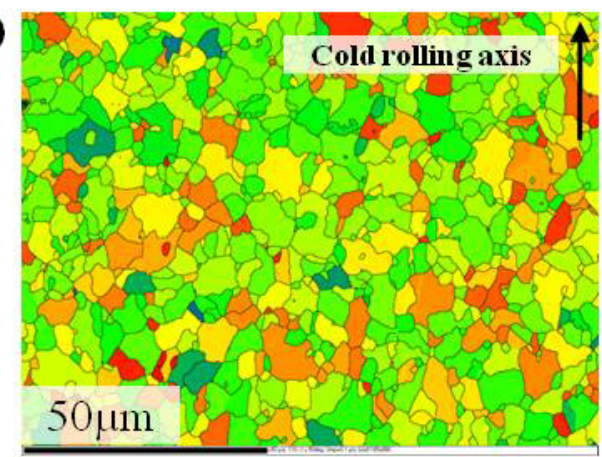

Color code of EBSD Scan: angle between $\langle 110\rangle$ and $x$ ory axis (radial direction of the tube) from $0^{\circ}$ (red) to $50^{\circ}$ (blue)

Corresponding Author name: Toualbi

Column width: 2 
Figure 7

EBSD scans and related experimental inverse pole figure obtained on the a) transverse and b) longitudinal cross-sections of cladding tube after final heat treatment

a)

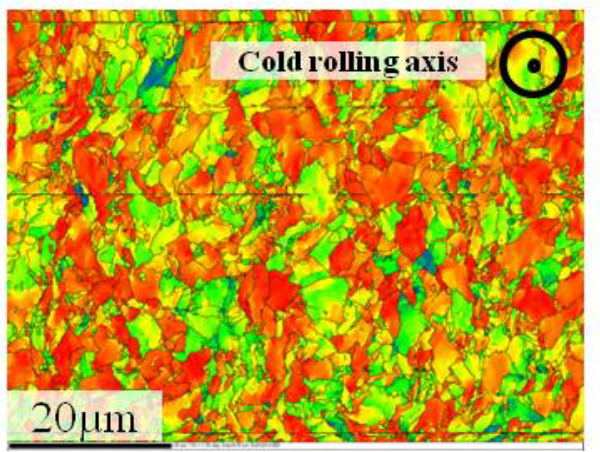

Color code of EBSD scan: angle between $\langle 110\rangle$ and $z$ axis (rolling axis) from $0^{\circ}$ (red) to $50^{\circ}$ (blue)

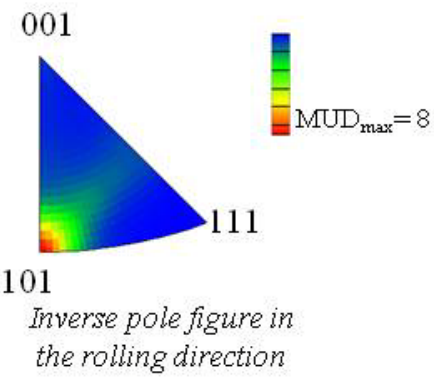

Inverse pole figure in

b)

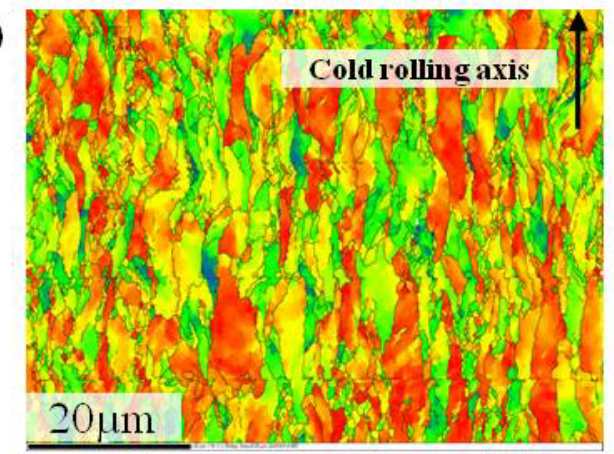

Color code of EBSD scan: angle between $\langle 110\rangle$ and $x$ ory axis (radial direction of the tube) from $0^{\circ}\left(\right.$ red) to $50^{\circ}$ (blue)

Corresponding Author name: Toualbi

Column width: 2 
Figure 8

Transmission electron micrographs of 9Cr-ODS martensitic cladding tube after final heat treatment
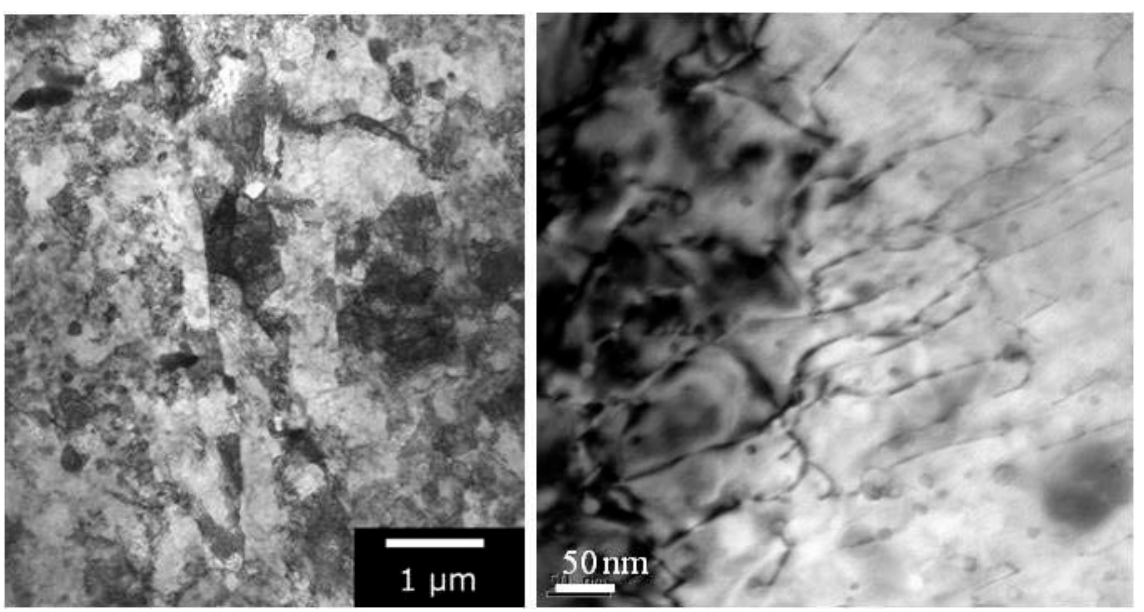

Corresponding Author name: Toualbi

Column width: 2 
Figure 9

SANS measurements on Fe-14Cr-1W extruded bar (dotted line) Fe-9Cr-1W extruded bar (dashed line) and cladding tube after final heat treatment (continuous line)

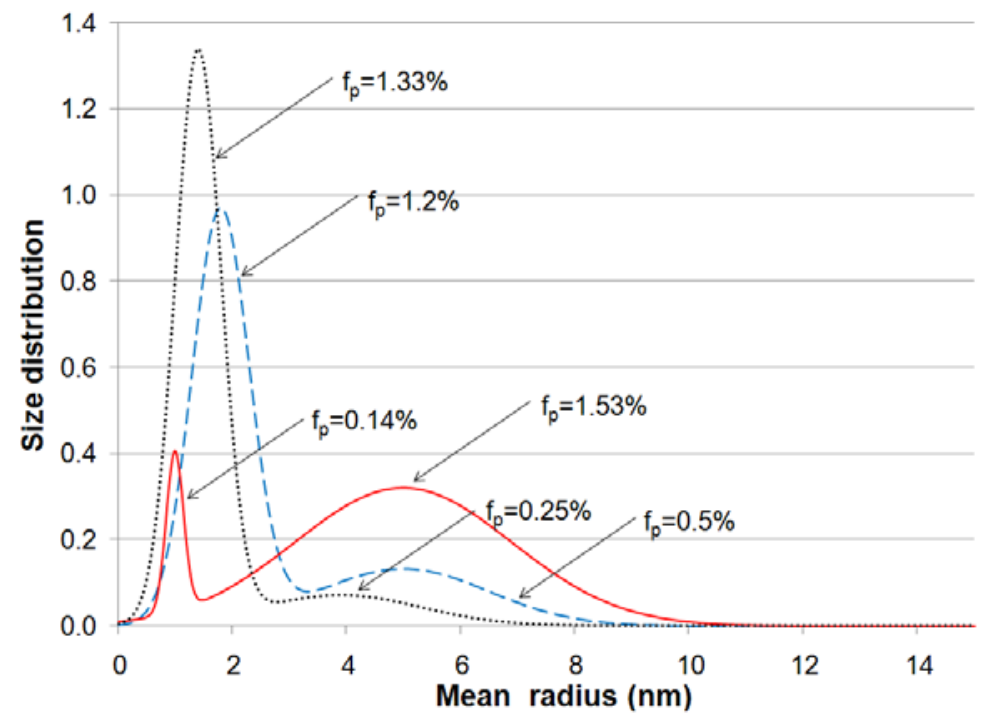

Corresponding Author name: Toualbi

Column width: 1 
Figure 10

Comparison of ultimate tensile strength between a conventional 9Cr steel P92 (dashed line) and three different grades of 9Cr-ODS martensitic steels: 9Cr-2W ODS cladding tube manufactured at JAEA (filled circles), 9Cr-2W ODS cladding tube elaborated through a JNC/CEA collaboration (empty circles) and 9Cr1W cladding tube manufactured by a high temperature fabrication route at CEA (filled squares).

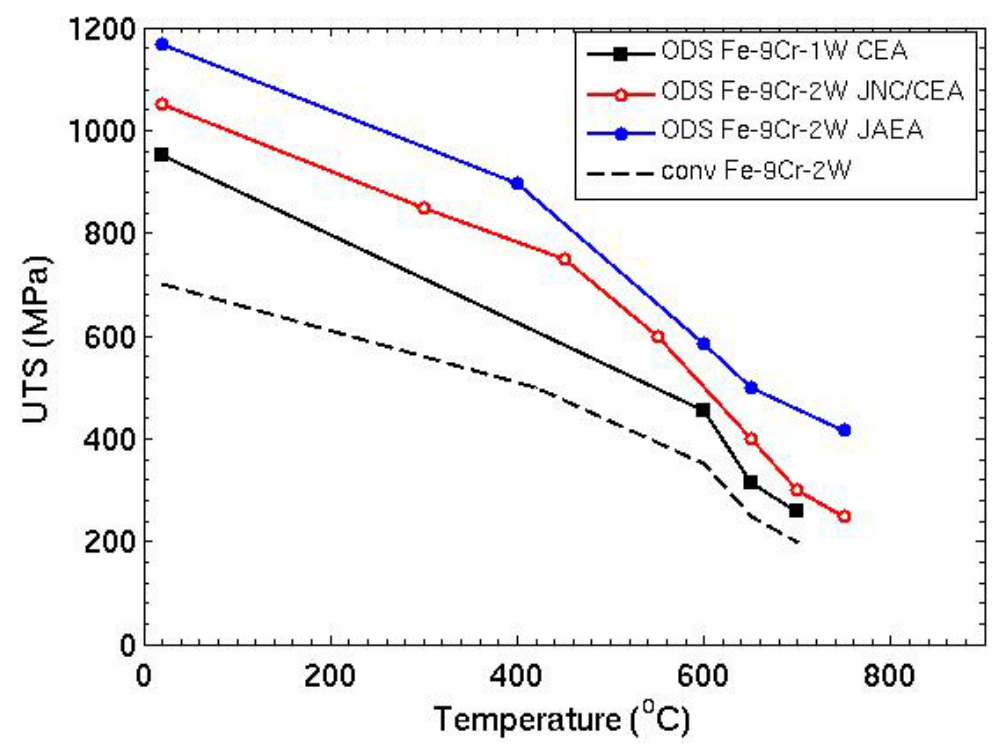

Corresponding Author name: Toualbi

Column width: 1 